\title{
Research on Energy-Environment-Economy-Ecology Coupling Development in the Yellow River Basin
}

\author{
Jinhui Zhao ${ }^{1}$, Lin Tian ${ }^{1, *}$, Lin Ding ${ }^{1}, \mathrm{He} \mathrm{Sun}^{1}$, and Puxi $\mathrm{Li}^{2}$ \\ ${ }^{1}$ School of Mechanical and Power Engineering, Zhengzhou University, 450001 Zhengzhou, Henan, China \\ ${ }^{2}$ International College, Zhengzhou University, 450001 Zhengzhou, Henan, China
}

\begin{abstract}
The Yellow River Basin is a major economic development area in China, and the high quality development of the basin still has great room for improvement. The coordinated development of energy, environment, economy and ecology is one of the keys to high quality development of the watershed. Aiming at the problem of energy, environment, economy and ecology restricting and promoting, this paper takes the nine provinces of the Yellow River as the research object, based on data from 2004 to 2017, through establishing the coupling coordination system of ecology, environment, economy and energy, using CRITIC method to study the characteristics of each subsystem of the basin in time and space. The results show that the score of energy, environment, economy and ecology is phased in time, and the level of compound coupling coordination is increasing year by year and the growth rate is obvious. The coupling coordination degree of the Yellow River basin has significant stage and regional characteristics in time and space, the coordination degree of the upper and middle reaches is higher than the coordination degree of the downstream coupling, but the difference between the three is gradually reduced with time.
\end{abstract}

\section{Introduction}

In recent years, China has issued and implemented major strategies for the development of the Yangtze River economic belt, the construction of Guangdong-Hong Kong-Macau Greater Bay Area, and the coordinated development of Beijing, Tianjin and Hebei, which provide a strong impetus for regional development. In this context, in order to form a high quality development model of the Yellow River Basin, General Secretary Xi Jinping clearly put forward a major national strategy for ecological protection and high quality development of the Yellow River Basin at the 2019 forum on ecological protection and high quality development of the Yellow River Basin [1].

The Yellow River Basin is rich in energy resources, coal, oil, natural gas and non-ferrous metal resources, known as China's "energy basin"[2]. However, with the development of society, the problem of insufficient support capacity of energy elements has gradually emerged, and the extensive industrial development model has been restricted by more stringent elements. Soil erosion, river siltation and lack of water resources in the basin have caused problems such as low carrying capacity of the ecological environment, frequent drought and flood disasters and competitive water use. Water shortage in the Yellow River basin is serious ${ }^{[3]}$. The current economic development of the Yellow River Basin lags behind the national average ${ }^{[4]}$. From 2010 to 2019 , the proportion of the total economic volume in the whole country decreased from 28.54 percent to 24.97 percent. The economic and social development of the basin lags behind that of the whole country. The foundation is poor and the economic vitality is lacking. Therefore, the coordinated development of energy, environment, economy and ecology in the Yellow River Basin has become one of the objective requirements for high quality and sustainable development. It is beneficial to explore the concept of high quality development and to guide the development direction of the Yellow River Basin to explore and analyze the coupling coordination level of energy, environment, economy and ecology.

\section{Literature review}

\subsection{Status of research}

Since the reform and opening up, China's economy has developed rapidly, but large energy, environmental pollution and ecology destruction have gradually become the main factors hindering the development of high quality. Therefore, scholars at home and abroad have done $3 \mathrm{E}$ (research on three systems: energy-environment-economy) and REE (resources-environment-economy). Foreign evaluation of energy-environment-economic system coordination is relatively early and David Hawdon [5] analyzes the relationship between the economy, energy and environment, and uses ENDAM model to simulate. Liu Huaqiao ${ }^{[6]}$ took Ningxia as the research object. The evaluation index system of energy-economy-environment

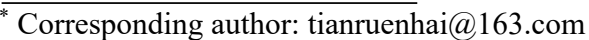


(3E) system is constructed, and the coordination degree of $3 \mathrm{E}$ system is analyzed by using the entropy method and coupling coordination degree. $\mathrm{Li}$ Xiaofei ${ }^{[7]}$ based on the time series data from 2000 to 2014 in Henan Province, the energy-economy-environment VAR model is constructed, and the dynamic relationship between energy, economy and environment in Henan Province is studied by using impulse response function and variance decomposition method. Some policy measures and suggestions are given from the aspects of industrial structure upgrading, environmental pollution prevention and control, air pollution prevention and control and social and economic sustainable development. $\mathrm{Li}^{\left[{ }^{[8]}\right.}$ used an exploratory spatial data analysis (ESDA) tool and PLS path model, the spatial distribution characteristics, dynamic evolution law and spatial agglomeration effect of coupling and coordinated development of provincial economy-energy-environment (3E) composite system are discussed.

However, REE (resource-environment-economy) system is characterized by different interactions among different sub-system elements ${ }^{[9]}$. WANG ${ }^{[10]}$ took Shandong Province as the research object and this paper evaluates its economic-energy-environment system from 2004 to 2012; Tian Bingbing ${ }^{[11]}$ based on Hangzhou as the research object, this paper constructs the comprehensive evaluation index system of Hangzhou's resource environment and economic development level, calculates the coordination value of Hangzhou from 2008 to 2017, and puts forward some countermeasures and suggestions for the sustainable development of Hangzhou; Cao Yan ${ }^{[12]}$ based on the data of forest resources, environment condition and economic development level of Fujian Province from 2007 to 2017, the evaluation index system of forest resources-economy-environment system in Fujian Province is constructed, and the optimization direction of ecological development in Fujian Province is put forward; Wang Xueqin ${ }^{[13]}$ took Shanxi Province as an example, established the coal industry REE (resourceenvironment-economy) system coupling and coordination degree evaluation system, and analyzed its level.

This shows that the research methods mainly focus on 3E systems or REE system ternary relationship, the coupling theory of the two systems, research methods are relatively mature, but because of the different focus of the sides and there is a certain bias, not comprehensive enough. These deficiencies provide space for the study of the coordinated development of energy, economy, environment and ecology in the Yellow River Basin. Based on the data of energy, economy, environment and ecology of 9 provinces in the Yellow River Basin from 2004 to 2017, this paper adopts the CRITIC method. In order to analyze comprehensive development of the Yellow River basin, analyze the coordinated development level of energy, economy, environment and ecology in the Yellow River basin, and put forward the optimization direction.

\subsection{Coordination Development Mechanism}

In the relationship between ecology and energy, the ecology of the Yellow River Basin is limited, and they need to be restrained in the process of energy and use; Improving energy development and utilization to increase the level of energy conservation is the high quality development of the Yellow River Basin basis. In the relationship between energy and the environment, most of the metabolites of energy in its consumption process are discharged into the atmospheric environment in different forms, which affect atmospheric quality and climate change. The change in atmospheric environmental quality and climate will affect the process of energy utilization and the supply of energy in the form of negative feedback. In the relationship between energy and the economy, energy is the material basis of economic development, and the growth of total energy, especially the promotion of industrialization, plays a role in promoting economic growth. In the relationship between ecology and the environment, the unreasonable exploitation of ecology will lead to environmental destruction, such as crowding out environmental water for industrial agriculture and making it near extinction, which will inevitably cause great damage to the environment, resulting in reduced vegetation coverage, shrinking natural oases and desertification.

\section{Methodology}

\subsection{CRITIC methods}

The CRITIC method is a weighting method based on the degree of indicator variation and the correlation between indicators. When the degree of variation of an indicator is greater, the indicator contains more information and the weight should be greater. At the same time, when there is a strong correlation between an indicator and other indicators, it means that the information contained in the indicator has been included by other indicators. See reference for the specific calculation method ${ }^{[14]}$.

\subsection{Coupling Cooperative Scheduling Model}

Coupling coordination degree model is used to analyze the level of coordinated development of things. Coupling degree can reflect the degree of mutual dependence and mutual restriction between systems, and coordination degree can reflect the quality of coordination. The coupling coordination degree model involves the calculation of three index values, namely the coupling degree value, the coordination degree value and the coupling coordination degree value. Combining the coupling coordination degree value and the coordination level classification standard, the coupling coordination degrees of each item can be obtained. See related literature for the construction process ${ }^{[15]}$.

\subsection{Evaluation system}

As a reflection of the importance of the index, the weight should be objective and accurate. CRITIC method is used to determine the weight of each provincial factor layer, and then the final weight of the index system of high 
quality development level in the Yellow River Basin is obtained by using the weighted average method. The index system of energy, environment, economy and ecology in the Yellow River Basin and the calculation results of the weight of each index is shown in Table1.

Table 1 Energy-Environment-Economy-Ecology Index System

\begin{tabular}{|c|c|c|c|c|}
\hline $\begin{array}{l}\text { Target } \\
\text { layer }\end{array}$ & $\begin{array}{l}\text { Criteria } \\
\text { layer }\end{array}$ & Element's layer & $\begin{array}{l}\text { Indicator } \\
\text { attributes }\end{array}$ & Weight \\
\hline \multirow{19}{*}{$\begin{array}{l}\text { High } \\
\text { quality } \\
\text { develop } \\
\text { ment } \\
\text { level }\end{array}$} & \multirow{5}{*}{ Ecology } & $\begin{array}{c}\text { Per capita } \\
\text { cultivated land } \\
\text { area }\end{array}$ & + & 0.05481 \\
\hline & & $\begin{array}{c}\text { Water resources } \\
\text { per capita }\end{array}$ & + & 0.04472 \\
\hline & & Forest cover & + & 0.05226 \\
\hline & & $\begin{array}{l}\text { Proportion of } \\
\text { total water } \\
\text { consumed by } \\
\text { industrial water }\end{array}$ & - & 0.05139 \\
\hline & & $\begin{array}{c}\text { GDP water } \\
\text { consumption per } \\
\text { unit }\end{array}$ & - & 0.03177 \\
\hline & \multirow{6}{*}{$\begin{array}{l}\text { Environ } \\
\text { ment }\end{array}$} & $\begin{array}{c}\text { Industrial } \\
\text { wastewater } \\
\text { discharge }\end{array}$ & - & 0.06269 \\
\hline & & Emissions & - & 0.03312 \\
\hline & & $\begin{array}{l}\text { Total amount of } \\
\text { industrial solid } \\
\text { waste }\end{array}$ & - & 0.06533 \\
\hline & & $\begin{array}{c}\text { Integrated } \\
\text { utilization of } \\
\text { industrial solid } \\
\text { waste } \\
\end{array}$ & + & 0.03753 \\
\hline & & $\begin{array}{l}\text { Industrial } \\
\text { pollution control } \\
\text { completed } \\
\text { investment }\end{array}$ & + & 0.03602 \\
\hline & & $\begin{array}{l}\text { GDP share of } \\
\text { expenditure on } \\
\text { energy } \\
\text { conservation and } \\
\text { environmental } \\
\text { protection }\end{array}$ & + & 0.03759 \\
\hline & \multirow{7}{*}{ Economy } & GDP growth rate & + & 0.06040 \\
\hline & & GDP per capita & + & 0.03367 \\
\hline & & $\begin{array}{c}\text { Total fixed assets } \\
\text { investment }\end{array}$ & + & 0.03440 \\
\hline & & $\begin{array}{l}\text { Total retail sales } \\
\text { of consumer } \\
\text { goods }\end{array}$ & + & 0.03314 \\
\hline & & Primary sector & - & 0.02862 \\
\hline & & Secondary sector & - & 0.03979 \\
\hline & & $\begin{array}{c}\text { Proportion of } \\
\text { tertiary industry }\end{array}$ & + & 0.03277 \\
\hline & Energy & $\begin{array}{l}\text { Share of coal } \\
\text { consumption }\end{array}$ & - & 0.03214 \\
\hline
\end{tabular}

\begin{tabular}{|l|l|c|c|c|}
\hline \multirow{n}{*}{} & $\begin{array}{c}\text { Share of oil } \\
\text { consumption }\end{array}$ & + & 0.04087 \\
\cline { 3 - 5 } & $\begin{array}{c}\text { Proportion of } \\
\text { natural gas } \\
\text { consumption }\end{array}$ & + & 0.03388 \\
\cline { 3 - 5 } & $\begin{array}{c}\text { Energy elasticity } \\
\text { coefficient }\end{array}$ & - & 0.03069 \\
\cline { 3 - 5 } & \begin{tabular}{c} 
Energy per G DP \\
\cline { 2 - 4 }
\end{tabular} & - & 0.03326 \\
\cline { 3 - 5 } & Energy per capita & - & 0.05911 \\
\hline
\end{tabular}

\section{ANALYSIS OF RESULTS}

\subsection{Comprehensive score analysis}

The comprehensive score of energy, environment, economy and ecology subsystem in the Yellow River Basin is shown in figure 1 , the comprehensive score of energy-environment-economy-ecology composite system which consists of four subsystems: energy, environment, economy and ecology, the biggest increase was in 20152016. Overall, the comprehensive score of each subsystem of the Yellow River Basin has a stage in time: the first stage is 2004-2010, environmental subsystems score the highest and there is a big difference with its remaining subsystem; The second phase, the ecology subsystem scores the highest; Phase III ,2014-2017, the economic subsystem scored the highest, and there are obvious differences with other subsystems. Before 2009, because of the low level of economic development, less pollution to the environment, so the environmental subsystem score higher than the other subsystems. But after 2009, the environmental subsystems were affected by environmental pollution from industrial development. The score shows the trend of fluctuation and decline; Low overall energy subsystem score, a trend of upward volatility; Economic sub-system scores are growing. There was a downward trend in 2005-2008. Affected by the 12th Five-Year Plan for Economic Development, Economic subsystems score faster. Although the score of economy subsystem fluctuates greatly between 2006 and 2009 (minus first and then increasing), the overall trend is increasing.

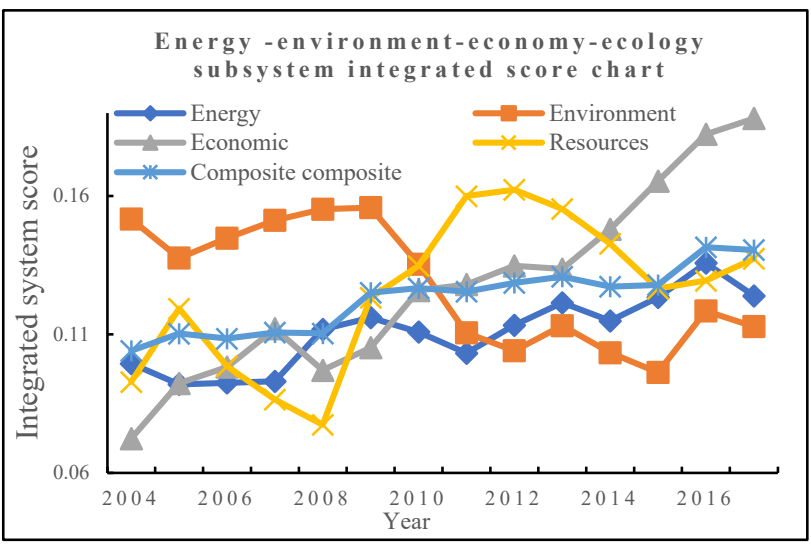

Figure 1. Integrated score of energy-environment-economyecology subsystem 


\subsection{Analysis of Coupling Coordination Degree of Dual Systems}

Table 2. Energy - environment - economy - ecosystem coupling

\begin{tabular}{|c|c|c|c|c|}
\hline Year & $\begin{array}{c}\text { Energy-environment } \\
\text { coupling coordination }\end{array}$ & $\begin{array}{c}\text { Energy-economic coupling } \\
\text { coordination }\end{array}$ & $\begin{array}{c}\text { Energy-economy coupling } \\
\text { coordination }\end{array}$ & $\begin{array}{c}\text { Composite coupling } \\
\text { coordination }\end{array}$ \\
\hline 2004 & Primary coordination & Moderate disorders & In danger & Moderate disorders \\
\hline 2005 & Moderate disorders & Moderate disorders & Moderate disorders & Moderate disorders \\
\hline 2006 & Mild disorders & Moderate disorders & Moderate disorders & Moderate disorders \\
\hline 2007 & In danger & Mild disorders & Moderate disorders & Moderate disorders \\
\hline 2008 & Good coordination & Coherent coordination & Moderate disorders & Coherent coordination \\
\hline 2009 & Good coordination & Primary coordination & Intermediate coordination & $\begin{array}{c}\text { Intermediate } \\
\text { coordination }\end{array}$ \\
\hline 2010 & Intermediate coordination & Primary coordination & Intermediate coordination & $\begin{array}{c}\text { Intermediate } \\
\text { coordination }\end{array}$ \\
\hline 2011 & Coherent coordination & Coherent coordination & Intermediate coordination & Primary coordination \\
\hline 2012 & Coherent coordination & Intermediate coordination & Good coordination & $\begin{array}{c}\text { Intermediate } \\
\text { coordination }\end{array}$ \\
\hline 2013 & Primary coordination & Intermediate coordination & Good coordination & Good coordination \\
\hline 2014 & Coherent coordination & Intermediate coordination & Intermediate coordination & $\begin{array}{c}\text { Intermediate } \\
\text { coordination }\end{array}$ \\
\hline 2015 & Moderate disorders & Good coordination & Good coordination & Good coordination \\
\hline 2016 & Intermediate coordination & Quality coordination & Good coordination & Quality coordination \\
\hline 2017 & Primary coordination & Quality coordination & Good coordination & Quality coordination \\
\hline
\end{tabular}

From the point of view of energy-environment coupling coordination state, the medium term coupling situation is excellent, reaching "high quality coordination" in 2008-2009, and rapidly deteriorating after 2011, 2017 is in "primary coordination ". The score of energy and environment subsystems increased simultaneously in the medium term, but the impact of energy on the environment has not yet been shown. In recent years, the extensive economic development of the Yellow River Basin has led to the increase of energy demand, the increasingly serious damage to the environment, the fragile environment of the basin cannot support the extensive use of energy, and the environment is under excessive pressure.

From the point of view of energy-economic coupling coordination state, the coupling level is increasing year by year, from "moderate imbalance" in 2004 to "high quality coordination" in 2017". The high coupling between energy and economy in the later period shows that energy plays a very important role in promoting the economy, while the economy plays a role in driving the growth of energy.

From the point of view of the coupling coordination state of energy and ecology, the coupling coordination level between the two is low in the early stage, mainly "moderate imbalance", and the latter stage reaches" good coordination ". However, compared with the level of energy-economic coupling coordination, there is still a large room for optimization. According to the weight of the subsystem, the energy utilization ratio is low, the energy is reduced, and the negative impact on ecology is great.

In a word, the complex coupling co-dispatching is increasing year by year and the growth rate is obvious. The coordination state is gradually changed from "moderate imbalance" to "high quality coordination", which indicates that the existing concept of high quality development in the Yellow River Basin is scientific and reasonable.

\subsection{Analysis of Coupling Coordination in Upper, Middle and Lower reaches of the Yellow River Basin}

The Yellow River Basin is divided into the upper reaches (Qinghai, Sichuan, Gansu, Ningxia, Inner Mongolia), middle reaches (Shaanxi and Shanxi), lower reaches (Henan and Shandong). The coupling values of each part are weighted average to obtain the comprehensive score of upper, middle and downstream (Figure 2.). The coupling coordination degree of the upper, middle and lower reaches of the Yellow River basin has remarkable characteristics in time and space. In space, the watershed coupling and coordination degree have a certain regionality, with the middle and upper reaches of the coordination degree being higher, and the downstream coupling and coordination degree being the lowest, located at the bottom of the three curves. In time, the coordination degree of basin coupling has a certain stage, 2011 as a watershed. In the early stage, the middle swim coupling co-scheduling is the highest, and the difference between upper, middle and lower reaches is great. Later downstream coupling coordination degree increased faster the differences between the three gradually narrowed. Before 2009, influenced by the strategy of "western development", the coupling coordination degree in the upper and middle reaches has a rapid growth. Since the implementation of the 12th Five-Year Plan, the provinces and districts have implemented measures such as 
industrial reform, ecological protection and optimal development. To sum up, the upper, middle and lower reaches show an increasing trend, and the difference of coupling coordination among the three is gradually reduced.

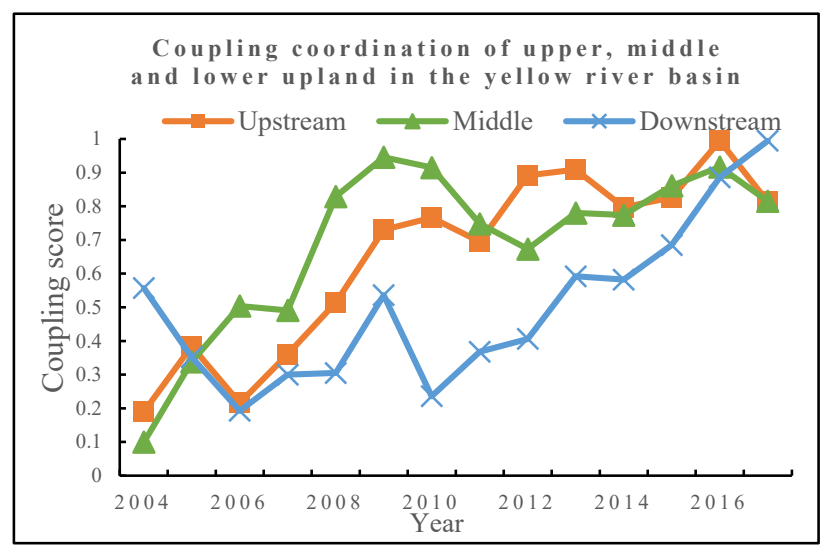

Figure 2. Coordination score of energy-environment-economyecology coupling in upper, middle and lower reaches of the Yellow River basin

\section{Optimization of system development}

1. The comprehensive score of energy-environmenteconomy-ecology subsystem (Figure 1.) shows that the extensive economic development of the Yellow River basin leads to the low score of the environmental subsystem. The provinces and districts of the basin should strengthen the concept of high quality development, pay attention to the green transformation of industries, encourage the development of tertiary industry and hightech industry, which belong to low energy industries. The development of the two can effectively control energy without affecting economic development. Implement energy structure reform, reduce coal consumption increase the proportion of natural gas in energy, and promote the research and application of new energy.

2. The coupling of energy, environment, economy and ecology system (Table 2) shows that the coordinated scheduling of composite couplings is increasing year by year, but there is still much room for optimization from the level of dual coupling coordination, especially the coordination level of energy and environment, which is only 0.672 in 2017. Watersheds can actively guide industry and commerce, enterprises and institutions in the urban and rural residents to implement electricity substitution and promote the growth of clean electricity consumption. In energy, electricity instead of oil, electricity instead of coal, promote the use of all kinds of domestic power products, production of power equipment and electric vehicles. Reduce the consumption of fossil energy, promote the optimization and upgrading of industrial structures, change the mode of economic development, improve the environment and improve efficiency, reduce the emission of pollutants, and protect the environment.

3. The energy-environment-economy-ecology coupling coordination score (Figure 2.) in the upper middle and lower reaches of the Yellow River basin shows that the upper middle and lower reaches of the coupling coordination situation are regional in space. In view of the unbalanced development of the upper and lower basins of the Yellow River, the provinces and districts should carry out regional coordination, set a good position from the toplevel design, arrange the bureau, plan as a whole, and coordinate the development. To establish and perfect the system of cross-regional coordination within the basin, to clarify the relationship between power and responsibility, and to realize the cross-regional coordination of ecological protection in the Yellow River basin. It is necessary to fully consider the differences between the upper and lower reaches, and encourage the local governments of the upstream and downstream regions to form a cross-regional cooperative governance mechanism of "cost sharing and benefit sharing" in the upstream and downstream regions. To guide the development of the Yellow River Basin to realize the "inter-regional" coordination, the so-called "regional" division in the intra-regional coordination cannot be limited to the existing administrative divisions, urban agglomeration planning, we should improve the upstream and downstream adjacent urban planning docking mechanism, co-governance mechanism and coordination mechanism.

\section{CONCLUSIONS}

1. The integrated score shows that the energyenvironment-economy-ecology subsystem scores are phased in time, with the first stage in 2004-2010, with the highest score for the environmental subsystem and a large gap with its remaining subsystems; the second stage in 2010-2014, with the highest score for the ecology subsystem; and the third stage in 2014-2017, with the highest score for the economic subsystem and a significant gap with other subsystems.

2. Coupling (Table 2) shows that the level of energyenvironment coupling coordination is poor compared with the rest, with only 0.672 coordination in 2017 . The level of compound coupling coordination is increasing year by year and the growth rate is obvious. The binary coupling coordination level is generally on the rise, but there is still a large optimization space from the coordination degree data.

3. The upper-middle-lower coupling coordination degree of the Yellow River basin indicates (Figure 2.) that it has significant stage and regional characteristics in time and space, with higher coordination degree in the uppermiddle and lowest coordination degree in the lowerstream, and the highest in the early-middle-stream coupling coordination in 2011 as a watershed.

\section{References}

1. Xi J. (2019) Speech at the Symposium on Ecological Protection and High quality Development of the Yellow River Basin. J. Qiushi, 20:4-11.

2. Wang C. (2021) Focus on cohesion to promote high quality economic development in the Yellow River Basin. J. Shandong Party School newspaper, 7:1-3. 
3. Yang Y, Liu B, Cui C. (2021) Study on Water Evolution Characteristics and Identification of Water Resources in the Yellow River Basin. J. People's Yellow River, 43(1):61-66.

4. Ning C. (2020) Dynamic Evaluation of Synergy between Ecological Protection and Economic Development of Yellow River Basin J. People's Yellow River, 42(12) : 1-6.

5. Hawdon D, Pearson P. (1995) Input-output simulations of energy, environment, economy interactions in the UK J. People's Yellow River, 17(1) : 73-86.

6. Liu H. (2019) Evaluation and Analysis of Coordination Degree of Economic, Energy and Environmental Systems in Ningxia J. Science and Technology Economic Market, 12:60-114.

7. Li X, Zhao L, Lu K. (2018) Study on the dynamic relationship between Energy-Economic-Environment in Henan Province based on VAR Model J. Journal of Henan University of Technology, 19(1):48-71.

8. Fan F, Ren X, Liu Q. (2020) the Coupling Coordination Analysis of Resource-EnvironmentEconomic Systems in Iron and Steel Industry of China J. China Mining, 29(09):1-8.

9. Fan F, Ren X, Liu Q. (2020) the Coupling Coordination Analysis of Resource-EnvironmentEconomic Systems in Iron and Steel Industry of China J. China Mining, 29(09):1-8.

10. Wang Q et al. (2014) Coordinated development of energy, economy and environment subsystems-A case study J. Ecological Indicators, 46: 514-523.

11. Tian B, Jiang Y. (2019) the Coordinated Development of Resources J. Environment and Economy in Hangzhou Youth, 2:464-465.

12. Cao Y, Li B. (2019) the Dynamic Analysis of the Coordinated Development of Forest ResourcesEconomic-Environment System in Fujian Province J. Journal of Fujian Jiangxia University, 10(06):20-28.

13. Wang X, Sheng W. (2018) the Coupled and Coordinated Development of Regional Coal Industry Economic-Resource-Environment System, J. Coal Engineering, 50(10):196-200.

14. Zhao S, Tang S. (2019) Comprehensive evaluation of transmission network planning scheme based on improved analytic hierarchy process (AHP), CRITIC method and approximate ideal solution sequencing method, J. Power Automation equipment, 39(3):143162.

15. Li L, Hong X, Wang J, Xie X. (2018) Study on the coupling and coordinated development of economy energy environment system based on PLS and ESDA, J. Soft science, 32 (11): 44-48. 